\title{
MODE-MATCHING ANALYSIS OF SUBSTRATE-INTEGRATED WAVEGUIDE CIRCUITS
}

\author{
Jens Bornemann and Farzaneh Taringou
}

\author{
Department of Electrical and Computer Engineering, University of Victoria, \\ Victoria, BC, V8W 3P6, Canada
}

\begin{abstract}
A mode-matching approach is presented for the analysis of substrate-integrated waveguide (SIW) circuits. The numerical technique takes advantage of recently developed fabrication techniques employing rectangular-shaped via holes. Discontinuity models involving all-dielectric waveguides and sections with arbitrary numbers of vias are presented and combined into a powerful analysis tool which can be used straightforwardly for the design of SIW components. The influence of the overall substrate width on the circuit performance is investigated. It is found that the computational domain can be significantly reduced without impacting on the computed performances. A design example involving a back-to-back impedance transformer is presented. The results are verified by comparison with the commercially available field solver CST Microwave Studio.
\end{abstract}

Index Terms - Substrate-integrated waveguide technology, numerical modeling, mode-matching techniques, computer-aided design.

\section{INTRODUCTION}

Substrate-integrated waveguide (SIW) circuits form a reasonable compromise between microstrip and waveguide technologies [1]. Their advantages made an impact in the lower millimeter-wave frequency range [2], [3] where microstrip components are increasingly lossy and waveguides too bulky.

Although a large variety of different SIW components have been presented in the recent literature, actual circuit designs involve commercial field solvers such as Ansoft HFSS or CST Microwave Studio. While the accuracy of such packages is undisputed, their numerical effort in circuit optimization is tremendous and time-consuming. Thus other techniques, which are more tailored to waveguide-type modeling, have emerged. The Mode-Matching Technique (MMT) is used for dispersion analysis of SIWs [4], and the Boundary Integral - Resonant Mode Expansion (BI-RME) method for equivalent-circuit extraction [5]. One of the reasons for not using such techniques in the full-wave synthesis and optimization of SIW circuits is the circular shape of the via holes with respect to the Cartesian coordinate system of the principle SIW discontinuities which form the SIW component. With the emergence of new fabrication techniques, however, more arbitrary via shapes become feasible [2], [6], and rectangular and square via shapes have successfully been implemented [7].

Therefore, this paper presents a MMT approach for the analysis and design of SIW components with square via holes. The numerical procedure follows fundamental MMT principles [8] and uses an all-dielectric waveguide as a lowreflective SIW feed [9].

\section{THEORY}

Fig. 1 shows a SIW formed by ten equally spaced square via hole pairs with equivalent-width all-dielectric waveguide ports at both ends.

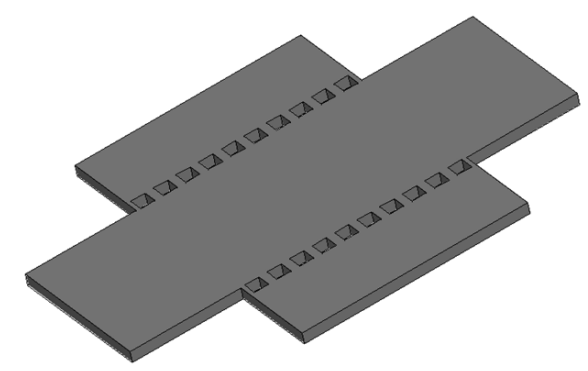

Fig. 1. Substrate-integrated waveguide with square via holes and all-dielectric waveguide ports.

In order to analyze such a circuit with a MMT procedure, two basic discontinuities need to be solved: first, the transition between two all-dielectric waveguides of different width (Fig. 2a) and, secondly, a number of rectangular vias embedded in an all-dielectric waveguide (Fig. 2b).

Since the substrate height is usually much smaller than the waveguide widths, a modal analysis based on $\mathrm{TE}_{\mathrm{m} 0}$ modes is sufficient. Following procedures in [8], the vector potentials in regions $v=-1,0, n(n=1$ to $N)$ (c.f. Fig. 2) can be written as

$$
\begin{aligned}
\mathrm{A}_{\mathrm{hz}}^{-1}=\sum_{\ell} \sqrt{\mathrm{Z}_{\ell}^{-1}} \mathrm{~A}_{\ell}^{-1} \cos \left\{\frac{\ell \pi}{\mathrm{a}_{-1}}\left(\mathrm{x}+\frac{\mathrm{a}_{-1}}{2}\right)\right\} \\
\cdot\left[\mathrm{F}_{\ell}^{-1} \exp \left(-j \mathrm{j}_{\mathrm{z} \ell}^{-1} \mathrm{z}\right)+\mathrm{B}_{\ell}^{-1} \exp \left(+\mathrm{jk}_{\mathrm{z} \ell}^{-1} \mathrm{z}\right)\right]
\end{aligned}
$$




$$
\begin{aligned}
A_{\mathrm{hz}}^{0}=\sum_{\mathrm{m}} \sqrt{\mathrm{Z}_{\mathrm{m}}^{0}} \mathrm{~A}_{\mathrm{m}}^{0} \cos \left\{\frac{\mathrm{m} \pi}{\mathrm{a}_{0}}\left(\mathrm{x}+\frac{\mathrm{a}_{0}}{2}\right)\right\} \\
\cdot\left[\mathrm{F}_{\mathrm{m}}^{0} \exp \left(-j \mathrm{k}_{\mathrm{zm}}^{0} \mathrm{z}\right)+\mathrm{B}_{\mathrm{m}}^{0} \exp \left(+\mathrm{jk}_{\mathrm{zm}}^{0} \mathrm{z}\right)\right] \\
\mathrm{A}_{\mathrm{hz}}^{\mathrm{n}}=\sum_{\mathrm{k}} \sqrt{\mathrm{Z}_{\mathrm{k}}^{\mathrm{n}}} \mathrm{A}_{\mathrm{k}}^{\mathrm{n}} \cos \left\{\frac{\mathrm{k} \pi}{\mathrm{a}_{\mathrm{n}}}\left(\mathrm{x}-\mathrm{x}_{\mathrm{n}}\right)\right\} \\
\cdot\left[\mathrm{F}_{\mathrm{k}}^{\mathrm{n}} \exp \left(-j \mathrm{k}_{\mathrm{zk}}^{\mathrm{n}} \mathrm{z}\right)+\mathrm{B}_{\mathrm{k}}^{\mathrm{n}} \exp \left(+j \mathrm{k}_{\mathrm{zk}}^{\mathrm{n}} \mathrm{z}\right)\right]
\end{aligned}
$$

where $\mathrm{F}$ and $\mathrm{B}$ are the forward and backward travelling wave amplitudes, respectively; $\mathrm{k}_{\mathrm{z}}$ are the propagation constants, A the normalization coefficients and $\mathrm{Z}$ the wave impedances, given by [8]

$$
\begin{aligned}
& \mathrm{k}_{\mathrm{zi}}^{v}=\sqrt{\left(\frac{\omega}{\mathrm{c}}\right)^{2} \varepsilon_{\mathrm{r}}-\left(\frac{\mathrm{i} \pi}{\mathrm{a}_{\mathrm{v}}}\right)^{2}} \\
& \mathrm{~A}_{\mathrm{i}}^{v}=\frac{\mathrm{a}_{\mathrm{v}}}{\mathrm{i} \pi} \sqrt{\frac{2}{\mathrm{a}_{\mathrm{v}} \mathrm{h}}} \\
& \mathrm{Z}_{\mathrm{i}}^{v}=\frac{\omega \mu_{0}}{\mathrm{k}_{\mathrm{zi}}^{v}}=\frac{1}{\mathrm{Y}_{\mathrm{i}}^{v}}
\end{aligned}
$$

$\mathrm{c}$ is the speed of light and $\mathrm{h}$ the substrate height.

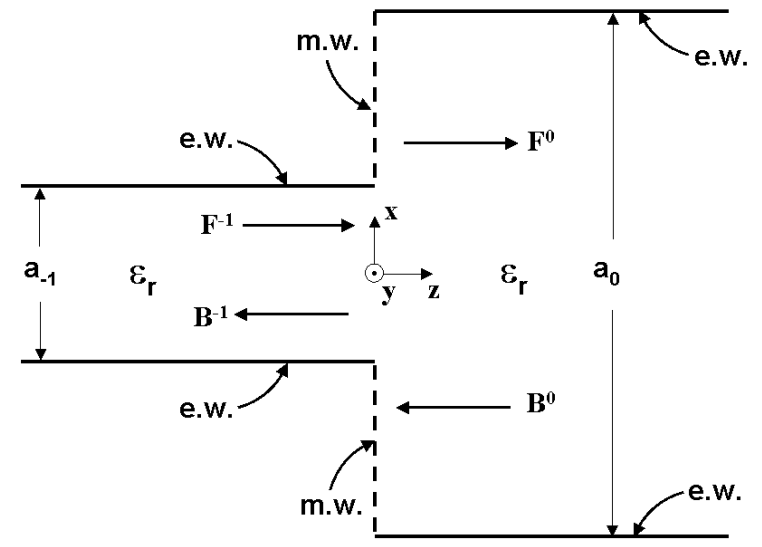

(a)

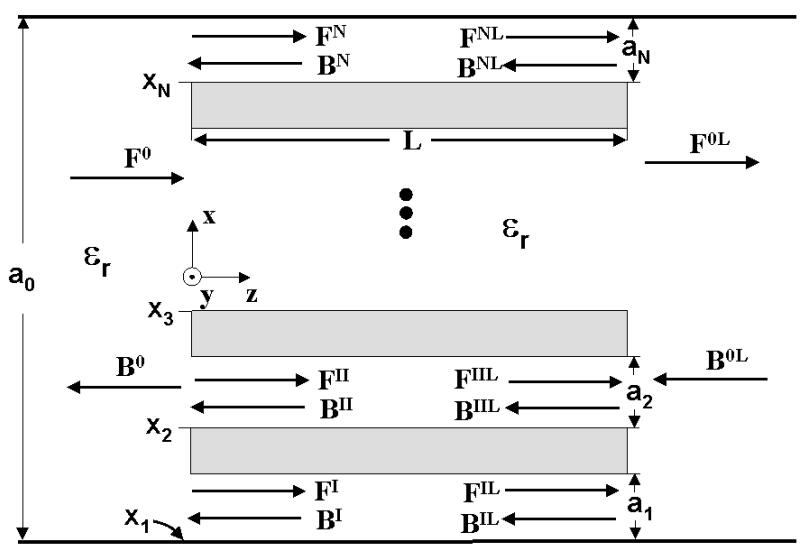

(b)

Fig. 2. Discontinuities involved in the MMT process.
Considering the magnetic-wall boundary conditions for the field-matching process in Fig. 2a, the coupling matrix for this discontinuity is

$$
\mathrm{M}=\operatorname{Diag}\left\{\sqrt{\mathrm{Y}_{\ell}^{-1}}\right\}(\mathrm{J}) \operatorname{Diag}\left\{\sqrt{\mathrm{Z}_{\mathrm{m}}^{0}}\right\}
$$

with

$$
(J)_{\ell \mathrm{m}}=\frac{2}{\sqrt{\mathrm{a}_{-1} \mathrm{a}_{0}}} \int_{-\mathrm{a}_{-1} / 2}^{+\mathrm{a}_{-1} / 2} \sin \left\{\frac{\ell \pi}{\mathrm{a}_{-1}}\left(\mathrm{x}+\frac{\mathrm{a}_{-1}}{2}\right)\right\} \sin \left\{\frac{\mathrm{m} \pi}{\mathrm{a}_{0}}\left(\mathrm{x}+\frac{\mathrm{a}_{0}}{2}\right)\right\} \mathrm{dx}
$$

from which the modal scattering matrix follows straightforwardly

$$
\begin{aligned}
& {\left[\begin{array}{c}
\mathrm{B}^{-1} \\
\mathrm{~F}^{0}
\end{array}\right]=\left[\begin{array}{ll}
\mathrm{S}_{11} & \mathrm{~S}_{12} \\
\mathrm{~S}_{21} & \mathrm{~S}_{22}
\end{array}\right]\left[\begin{array}{c}
\mathrm{F}^{-1} \\
\mathrm{~B}^{0}
\end{array}\right]} \\
& \mathrm{S}_{11}=\left[\mathrm{MM}^{\mathrm{T}}+\mathrm{U}\right]^{-1}\left[\mathrm{MM}^{\mathrm{T}}-\mathrm{U}\right] \\
& \mathrm{S}_{12}=2\left[\mathrm{MM}^{\mathrm{T}}+\mathrm{U}\right]^{-1} \mathrm{M}=\mathrm{S}_{21}^{\mathrm{T}} \\
& \mathrm{S}_{21}=\mathrm{M}^{\mathrm{T}}\left[\mathrm{U}-\mathrm{S}_{11}\right]=\mathrm{S}_{12}^{\mathrm{T}} \\
& \mathrm{S}_{22}=\mathrm{U}-\mathrm{M}^{\mathrm{T}} \mathrm{S}_{12}
\end{aligned}
$$

where $\mathrm{U}$ is the unit matrix, and $\mathrm{T}$ means transposed.

The discontinuity in Fig. $2 \mathrm{~b}$ involves $\mathrm{N}$ coupling matrices, capturing the coupling from region 0 to each region $\mathrm{n}(\mathrm{n}=1$ to $\mathrm{N})$. However, since the number of modes in region 0 is higher than that in region $\mathrm{n}$, the column-type coupling matrices are arranged in one large matrix with the single right side vector holding all forward and backward traveling wave amplitudes $\mathrm{F}^{\mathrm{n}}$ and $\mathrm{B}^{\mathrm{n}}$. The individual coupling matrices are

$$
M^{n}=\operatorname{Diag}\left\{\sqrt{Y_{m}^{0}}\right\}\left(J^{n}\right) \operatorname{Diag}\left\{\sqrt{Z_{k}^{n}}\right\}
$$

with

$$
\left(J^{n}\right)_{m k}=\frac{2}{\sqrt{a_{0} a_{n}}} \int_{x_{n}}^{x_{n}+a_{n}} \sin \left\{\frac{m \pi}{a_{0}}\left(x+\frac{a_{0}}{2}\right)\right\} \sin \left\{\frac{k \pi}{a_{n}}\left(x-x_{n}\right)\right\} d x
$$

With all $\mathrm{N}$ output-port amplitudes combined in a single-port vector, the scattering matrix of the $\mathrm{N}$-furcated waveguide discontinuity is as in (4b). The final modal scattering matrix of $\mathrm{N}$ via holes in an all-dielectric waveguide (Fig. 2b)

$$
\left[\begin{array}{c}
B^{0} \\
F^{0 L}
\end{array}\right]=\left[\begin{array}{ll}
S_{11 v} & S_{12 v} \\
S_{21 v} & S_{22 v}
\end{array}\right]\left[\begin{array}{c}
F^{0} \\
B^{0 L}
\end{array}\right]
$$

is obtained by cascading a single diagonal matrix containing the transmission parameters $D^{n}$ of every single region $n=1$ to $\mathrm{N}$ up to the center location $(\mathrm{z}=\mathrm{L} / 2)$ of the via holes (Fig. $2 \mathrm{~b}$ )

$$
\mathrm{D}^{\mathrm{n}}=\operatorname{Diag}\left\{\exp \left(-\mathrm{jk} \mathrm{k}_{\mathrm{zk}}^{\mathrm{n}} \frac{\mathrm{L}}{2}\right)\right\}
$$

and flipping the resulting scattering matrix, i.e., cascading the same scattering matrix but with input and output ports interchanged.

The final overall modal scattering matrix of the structure in Fig. 1 is then obtained by following general procedures of cascading scattering matrices, e.g. [8]. 


\section{RESULTS}

The first step in designing a substrate-integrated waveguide is to specify the substrate and the frequency range. For this work, the substrate is chosen as RT Duroid 5880 with a relative permittivity of $\varepsilon_{\mathrm{r}}=2.2$ and a substrate height of $\mathrm{h}=508 \mu \mathrm{m}$. For the frequency range of $18 \mathrm{GHz}$ to $28 \mathrm{GHz}$, a SIW cutoff frequency of approximately $15 \mathrm{GHz}$ was chosen which, following guidelines in [10], results in circular vias of diameters of $0.72 \mathrm{~mm}$ and center-to-center (longitudinal) spacings of $1.02 \mathrm{~mm}$. The (transverse) width of the SIW measured between the centers of the via holes is $\mathrm{a}_{\mathrm{via}}=7.28 \mathrm{~mm}$. The equivalent waveguide width of such an arrangement is $\mathrm{a}_{\text {equ }}=6.71 \mathrm{~mm}$ according to [11]. In order to employ the MMT procedure outlined in the previous section, the circular vias are translated to square ones based on the assumption that the area of the via hole be preserved. Thus all via holes used in this work have a cross section of $0.64 \mathrm{~mm} \times 0.64 \mathrm{~mm}$. Moreover, all examples presented below have been obtained using all modes up to $300 \mathrm{GHz}$ for the modeling of discontinuities and modes up to 150 $\mathrm{GHz}$ for the combination of modal scattering matrices.

The quality of a SIW circuit and its transition to an alldielectric waveguide of width $\mathrm{a}_{-1}=\mathrm{a}_{\text {equ }}$ (Fig. 2a) is measured by the reflection coefficient seen into the ports. Fig. 3 depicts the performance of the circuit shown in Fig. 1.

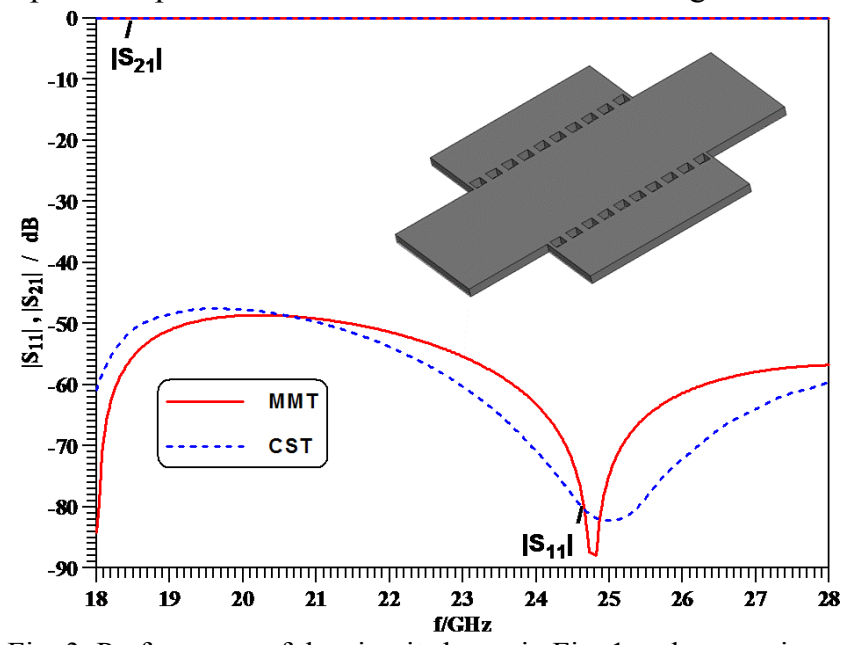

Fig. 3. Performance of the circuit shown in Fig. 1 and comparison between this method (solid lines) and CST (dotted lines).

The reflection coefficient is $-50 \mathrm{~dB}$ or better, and the results are confirmed by the commercial field solver CST Microwave Studio. For the CST simulations, the accuracy is set to the minimum limit of $-80 \mathrm{~dB}$. The agreement between the MMT approach presented here and the CST results is excellent and remarkable, especially considering the fact that the two curves that are compared are both at such a low level. This result instills confidence in the design of future SIW components. It is worthwhile to point out that a different computation of the equivalent waveguide width as recently published in [12] results in a reflection level that is $10 \mathrm{~dB}$ higher than that shown in Fig. 3 and thus is not as well matched to the SIW as the results obtained from [11].

Another critical point involving the computational domain is associated with the substrate width of the viaholed section ( $\mathrm{a}_{0}$ in Fig. 2). Therefore, the performance of the circuit in Fig. 3 has been re-evaluated using different substrate widths normalized to the center-to-center SIW width $\mathrm{a}_{\text {via }}$. The resulting performances are shown in Fig. 4. It is observed that the outer substrate walls can be located very closely to the via holes and that the performance is nearly independent of their actual location. Thus the computational domain for SIW circuit modeling can be reduced. As the substate wall distance is increased, a limit is reached $\left(a_{0} / a_{\text {via }}=3\right.$ in Fig. 4) when fields are propagating outside of the SIW and recombine with those in the actual SIW. Then resonance peaks as the one observed at $24.6 \mathrm{GHz}$ in Fig. 4 occur and will affect the accuracy of the MMT modeling process. As the substrate width is further increased (not shown here), more resonance peaks appear and make it difficult to obtain a reliable performance evaluation of a SIW circuit.

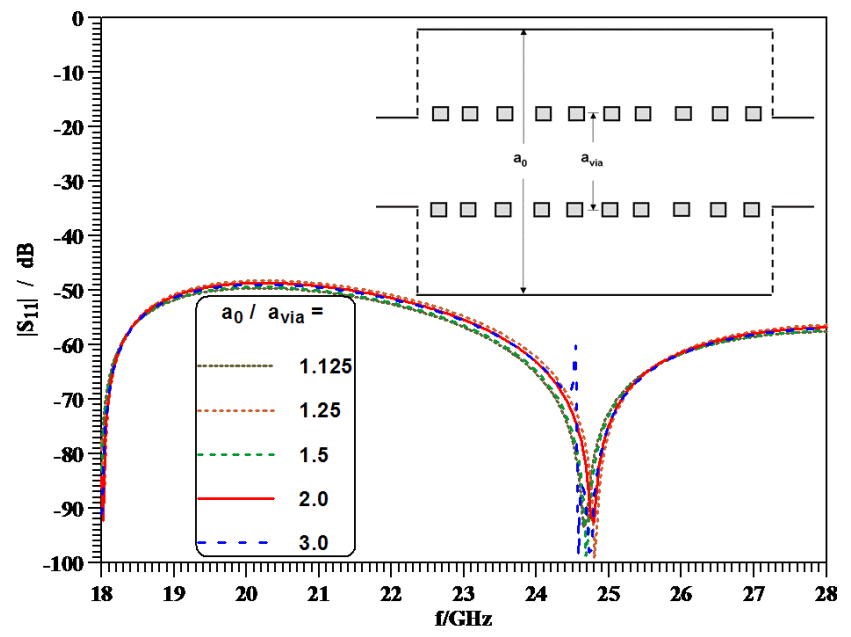

Fig. 4. Influence of the substrate width on the performance of the circuit in Fig. 1.

As a design example, Fig. 5 shows the performance of a back-to-back connection of a two-section impedance transformer in SIW technology. The transformer has been designed using a standard H-plane waveguide transformer synthesis routine [8]. As the exact corners and straight walls of the waveguide model cannot exactly be reproduced by the via holes in the SIW component, fine optimization of transformer lengths and width becomes necessary. For this purpose, additional vias are added at the transitions between different waveguide widths so that the width can be optimized without creating large spaces between via holes. As shown in Fig. 5b, excellent agreement is observed between the results of the MMT approach and those of CST, thus verifying the correctness of the MMT modeling process presented in this paper. Note that all $\mathrm{S}_{11}$ levels are below -40 dB. 


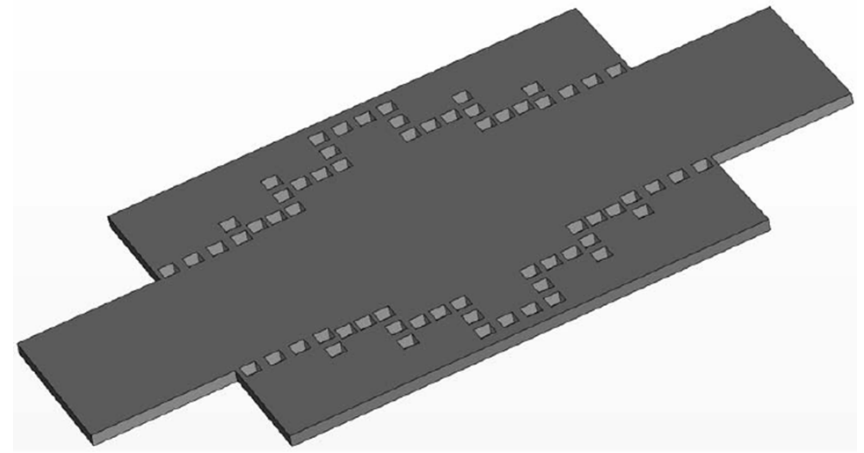

(a)

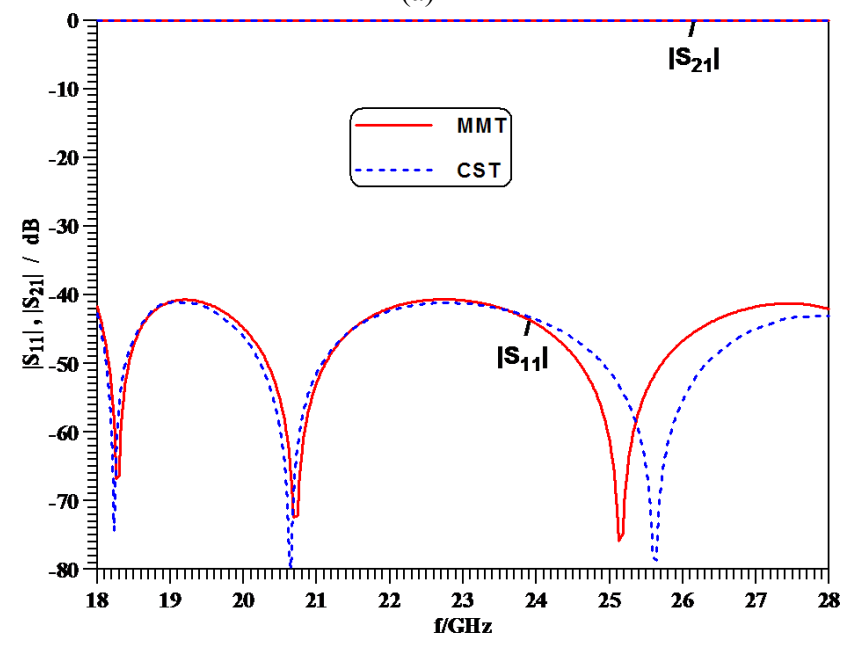

(b)

Fig. 5. A back-to-back two-section impedance transformer (a) and performance comparison (b) between this method (solid lines) and CST (dotted lines).

\section{CONCLUSIONS}

A modeling approach for the analysis and design of SIW circuits is presented. The mode-matching procedure takes advantage of via holes of square cross sections and captures the modal interactions of all individual discontinuities involved. An advantage of this technique is that the actual substrate width can be reduced to extend just a fraction beyond the vias which gives rise to a reduction in the overall computational domain.

Examples include a SIW section fed by all-dielectric waveguide ports and a back-to-back connection of a twosection impedance transformer. Excellent agreement with results obtained from CST Microwave Studio verifies the modeling process presented in this paper.

\section{REFERENCES}

[1] K. Wu, D. Deslandes, and Y. Cassivi, "The substrate integrated circuits - A new concept for high-frequency electronics and optoelectronics," Proc. 6th Int. Conf. Telecommunications in
Modern Satellite, Cable and Broadcasting Service (TELSIKS 2003), vol. 1, pp. PIII-PX, Oct. 2003.

[2] E. Moldovan, R.G. Bosisio, and K. Wu, "W-band multiport substrate-integrated waveguide circuits," IEEE Trans. Microwave Theory \& Tech., vol. 54, pp. 625-632, February 2006.

[3] D. Stephens, P.R. Young, and I.D. Robertson, "Millimeterwave substrate integrated waveguides and filters in photoimageable thick-film technology," IEEE Trans. Microwave Theory Tech., Vol. 53, pp. 3832-3838, Dec. 2005.

[4] H.R. Sadreazami, E. Mehrshahi, and R. RezaiesarIak, "Analysis of dispersion characteristic of substrate integrated waveguide based on mode matching method," Proc. Asia-Pacific Int. Symp. Electromagnetic Compatibility, pp. 1384-1386, Beijing, China, Apr. 2010.

[5] M. Bozzio and L. Perregrini, "Full-wave analysis and equivalent-circuit modeling of SIW components," Workshop Notes: Substrate Integrated Circuits, IEEE MTT-S int. Microwave Symp., May 2010.

[6] D. Hammou, E. Moldovan, and S. O. Tatu, "V-band microstrip to standard rectangular waveguide transition using a substrate intergrated waveguide (SIW)," J. Electromagn. Waves Appl., Vol. 23, pp. 221-230, 2009.

[7] D. Dousset, Développement de composants SIW dans la bande 3 d'ALMA (84-116 GHz) et conceptions d'une jonction orthomode (OMT) dans la bande 1 d'ALMA (31-45 GHz) en technology guide d'onde, PhD Dissertation, Université de Montréal, 2010.

[8] J. Uher, J. Bornemann and U. Rosenberg, Waveguide Components for Antenna Feed Systems. Theory and CAD. Artech House, Norwood, 1993.

[9] V.A. Labay and J. Bornemann, "E-plane directional couplers in substrate-integrated waveguide technology", Proc. 2008 AsiaPacific Microwave Conf., A1-75, 4 p., Hong Kong, Dec. 2008.

[10] Y. Cassivi, L. Perregrini, P. Arcioni, M. Bressan, K. Wu, and G. Conciauro, "Dispersion characteristics of substrate integrated rectangular waveguide," IEEE Microwave Wireless Comp. Lett., vol 12, pp. 333-335, Sep. 2002.

[11] L. Yan, W. Hong, G. Hua, J. Chen, K. Wu, and T.J. Cui, "Simulation and experiment on SIW slot array antennas," IEEE Microwave Wireless Comp. Lett., vol. 14, pp. 446-448, Sep. 2004.

[12] M. Salehi and E. Mehrshahi, "A closed-form formula for propagation characteristics of substrate integrated waveguide," Proc. Asia-Pacific Microwave Conf., pp.1494-1496, Yokohama, Dec. 2010. 